\title{
A FÍSICA NO COTIDIANO: \\ ENSINO E APRENDIZAGEM COM BASE NA TEORIA VYGOTSKYANA
}

\author{
Apresentação: Comunicação Oral \\ Almeida, J. C. ${ }^{1}$; ROCHA, F. P. ${ }^{2}$; DE CHIARO, S. ${ }^{3}$ \\ Universidade Federal de Pernambuco - Campus Recife.
}

\begin{abstract}
Resumo. Por ser uma ciência da natureza, a Física procura explicar fenômenos naturais através de conceitos e terminologias bem definidas, capaz de caracterizá-los, ou seja, a partir de uma representação simplificada do fenômeno é possível concluir diversas propriedades de tal sistema que se deseja estudar e compreender. Ela é constituída por modelos e teorias que procuram explicar a realidade, possibilitando um melhor entendimento do universo e do mundo em que nos cerca. Dessa forma, esse e outros argumentos são capazes de dar sustentação à manutenção da Física na formação básica dos estudantes. Porém, o aprendizado desta disciplina no ensino médio certamente não pode se basear apenas em como apresenta o livro texto, no treinamento de provas escolares ou focado nas provas de vestibulares, um ensino pragmático com aspecto uniforme baseado em decorar fórmulas e métodos mecânicos e repetitivos de resolver certas atividades. Por ser uma ciência experimental e de conceitos abstratos o seu ensino pode ser desenvolvido através de situações as quais estamos muitas vezes inseridos. Assim, partindo de uma concepção de ensino e de aprendizagem baseada na teoria sócio-histórica de Vygotsky, esse trabalho teve como objetivo a aplicação de estratégias didáticas no ensino da Física focadas na interação entre professor e aluno, entre os próprios alunos e no uso de materiais experimentais. Essas estratégias buscaram propiciar a compreensão dos alunos em relação às situações do cotidiano as quais envolvem alguns conceitos de Fluidos. A partir dessas práticas, foi possível observar que os alunos tiveram uma participação ativa no próprio processo de construção de conhecimentos sobre a temática abordada, visto que, os tutores, ao levarem em consideração a zona de desenvolvimento proximal de seus alunos, oportunizaram que os mesmos atuassem como agentes participativos e críticos do processo de aprendizagem.
\end{abstract}

Palavras-Chave: fluidos, teoria sócio-histórica de Vygotsky, mediação, ensino de Física.

\section{Introdução}

Por ser uma ciência experimental e de conceitos abstratos, a Física torna-se uma disciplina de difícil compreensão para muitos alunos pela dificuldade de associação com o mundo real. No ensino médio, essa característica é observada em proporções significativas,

\footnotetext{
${ }^{1}$ Licenciando em Física, Universidade Federal de Pernambuco, jeyvson10@gmail.com

${ }^{2}$ Licenciando em Física, Universidade Federal de Pernambuco, felipederocha02@gmail.com

${ }^{3}$ Doutorado em Psicologia Cognitiva, Universidade Federal de Pernambuco, chiaro@ hotlink.com.br
} 
sendo na maior parte das vezes causa para elevado desinteresse pelo aprendizado da disciplina. $\mathrm{O}$ uso de métodos tradicionais de ensino e a carência de estratégias pedagógicas que possibilitem essa vinculação dos conceitos com o dia a dia dos alunos, contextualizandoos, constituem uma das razões deste problema.

A Física surge para explicar os fenômenos naturais, sobre os quais qualquer teoria só tem significado real quando comprovada experimentalmente. É pouco provável, usando apenas canetas de tintas e lousa, representar a dinâmica de um evento em uma sequência de instantes (por exemplo, desenhos e animações). Na prática, a Física representa para o estudante, na maior parte das vezes, uma disciplina muito difícil, em que é preciso decorar fórmulas cuja origem e finalidades são desconhecidas.

Uma alternativa para estudarmos a Física é através da utilização de materiais experimentais, porém, os poucos laboratórios existentes e que funcionam, além de representarem elevado custo de montagem e manutenção, costumam ser ainda utilizados de forma tradicional e limitados, seguindo roteiros já estabelecidos e instrutivos. O ensino de ciências baseado, principalmente, em exposições metódicas sobre o assunto transmite uma ideia muito incompleta e muito pouco instigante do que é a ciência e de como ela se constrói.

No sentido de promover atividades que favoreçam o ensino e a aprendizagem dos conceitos de forma contextualizada e plena de sentido para os alunos, defendemos que o professor deve inicialmente conceber que o desenvolvimento de cada estudante se dá como resultado de um processo sócio-histórico e cultural, tendo a linguagem como principal sistema simbólico de mediação entre os mesmos e o mundo em que vivem. Para Vygotsky (2000), a compreensão sobre o desenvolvimento da linguagem e suas relações com o pensamento é crucial, especialmente no que se refere aos processos de aprendizado e desenvolvimento do indivíduo a partir de suas relações interpessoais e com o meio de forma geral.

Assim, o caráter sociocultural do ensino e da aprendizagem proposto por Vygotsky (1987) faz-se presente na mediação realizada através de signos/sistemas simbólicos, essencialmente na linguagem utilizada em atividades sociais diversas do dia-a-dia e na sala de aula, o que inevitavelmente leva o aprendiz a interagir com outros atores, colegas e professores. Este autor defende que ações de ensino devem ser consideradas mais efetivas quando agem naquilo que o mesmo chama de Zona de Desenvolvimento Proximal (ZDP), ou seja, distância entre o nível de desenvolvimento potencial (NDP) e o nível de desenvolvimento real do indivíduo (NDR).

A ZDP refere-se, portanto, ao caminho no processo de amadurecimento entre conseguir realizar algo com ajuda (nível potencial) e sozinho (nível real), mostrando assim ter 
consolidado uma nova função (Monteiro, 2012). Um dos papéis do professor é o de parceiro mais capaz, que atua na condução do processo de ensino e orienta a aprendizagem do estudante, por meio de interações sociais adequadamente planejadas.

Considerando esse conceito básico (ZDP), percebemos algumas estratégias a partir das quais o professor pode incidir sobre a ZDP dos alunos: a utilização e demonstração de experimentos simples para explorar os conteúdos e suas aplicações em noções conceituais, o estímulo ao desenvolvimento do pensamento conceitual partindo dos conhecimentos prévios dos aprendizes e a troca de informações através de trabalhos em grupo são formas relevantes de propiciar o desenvolvimento dos processos mentais dos envolvidos.

Dentro dessa perspectiva, pois, o docente deixa de ter o papel de agente de transmissão de informações e conhecimento, atuando como mediador na dinâmica das relações interpessoais e, principalmente, passando a ter a responsabilidade de conhecer seus alunos e seu grupo de modo, a saber, como e quando promover avanços no desenvolvimento deles. Inserir-se na ZDP dos alunos é partir daquilo que eles trazem, desafiando-os e apoiando-os na ampliação da construção de novos conhecimentos e habilidades, estimulando, portanto, a sua aprendizagem e, consequentemente, seu desenvolvimento.

O objetivo deste trabalho foi a utilização de procedimentos didáticos, baseados nos conceitos vygotskyanos, com o propósito de evidenciar aos alunos situações que envolvem fluidos (objeto de estudo da hidrostática) abordando algumas noções conceituais de Massa Específica, Densidade e Pressão, além do Teorema de Stevin e dos Princípios da Hidrostática (Princípio de Pascal e o Princípio de Arquimedes). A partir disso, aproximá-los de alguns fenômenos do cotidiano e de seus conhecimentos prévios, atuando na zona de desenvolvimento proximal dos mesmos assim como estimulando que eles também atuem na zona de desenvolvimento proximal uns dos outros dependendo da diferença na experiência de cada um nos diferentes conceitos trabalhados, e levá-los a um novo conhecimento e uma nova aprendizagem. Com isso, pretendemos mostrar a importância da mediação entre professor e aluno e entre os próprios alunos, além do uso de materiais experimentais que facilitem o aprendizado e desenvolvimento dos discentes.

\section{Fundamentação Teórica}

Partindo desse contexto, o processo ensino-aprendizagem de Física relaciona-se essencialmente ao campo das estruturas cognitivas dos indivíduos, a aprendizagem cognitiva. Em face disto, falar sobre o processo de construção de conhecimento do ensino dessa Ciência requer uma identificação com algumas teorias cognitivas de aprendizagem, como uma 
maneira de analisar certos mecanismos que propiciem o entendimento das definições conceituais e fenômenos físicos. Várias são as teorias que tem sido propostas como forma de auxiliar o ensino nos últimos anos, entretanto, algumas podem está intimamente ligadas com o ensino de Física.

Desse modo, essas teorias que ressaltam pensamentos construtivistas e buscam através do processo de construção do conhecimento o meio favorável a sua compreensão, parecem ser mais adequadas à proposta deste artigo. A partir disso, dentre as construtivistas, ressaltamos a teoria histórico-cultural que fornece percepção sobre como se efetiva uma aprendizagem baseada na apropriação do conhecimento, atribuindo uma importância ao papel da interação social no progresso do ser humano. Alguns estudos apontam para a inter-relação entre aprendizagem e desenvolvimento, contudo visam que aprendizagem não é desenvolvimento, já que avança de forma mais lenta e após o movimento de aprendizado. Segundo Vygotsky (1999, p.118):

(...) o aprendizado adequadamente organizado resulta em desenvolvimento mental e põe em movimento vários processos de desenvolvimento que, de outra forma, seriam impossíveis de acontecer. Assim, o aprendizado é um aspecto necessário e universal do processo de desenvolvimento das funções psicológicas culturalmente organizadas e especificamente humanas.

Assim, o desenvolvimento pleno do ser humano depende do aprendizado que ele estabelece em um determinado grupo cultural, com base na sua interação social com outros indivíduos. Sendo mais especifico, está relacionado com o processo de ensino e aprendizagem, Vygotsky (1999) certifica que "o bom ensino é aquele que se adianta ao desenvolvimento". Ao possibilitar a existência de zonas de desenvolvimento proximal, o professor estaria forçando o aparecimento de funções que ainda não estão desenvolvidas completamente. Para Vygotsky, as disciplinas escolares são capazes de nortear e estimular o desenvolvimento de funções mentais superiores ${ }^{4}$ uma vez que se ligam ao sistema nervoso central. Esse progresso possibilita um processo que envolve a interação do organismo individual com o meio físico social em que vive. E como se dá essa interação? Principalmente através da mediação.

\footnotetext{
${ }^{4}$ Mecanismos psicológicos mais sofisticados e complexos, típicos do ser humano e que envolvem controle consciente e ação intencional.
} 
A teoria sócio-histórico-cultural vygotkyana destaca a relação entre o social e a aprendizagem escolar. No ensino de Física, observa-se a importância dessa interação social no processo de aprendizagem escolar, visto que esta Ciência se encontra próxima e presente na realidade dos estudantes. Isto, por sua vez, enfatiza o caráter da teoria que se estabelece na relação entre determinados conceitos científicos (ambiente escolar) e os conceitos espontâneos (apropriados no cotidiano), como uma forma de facilitar a formação dos conceitos curriculares da disciplina. As proposições de Vygotsky a respeito deste processo de formação de conceitos possibilitam verificar a relação existente entre o pensamento e a linguagem, pelos quais ocorre a internalização do conhecimento, e as relações estabelecidas entre os conhecimentos cotidianos e os científicos.

O autor declara:

A formação de conceitos é o resultado de uma atividade complexa, em que todas as funções intelectuais básicas tomam parte. No entanto, o processo não pode ser, reduzido a associação, à atenção, à formação de imagens, à interferência ou as tendências determinantes. Todas são indispensáveis, porém insuficientes sem o uso do signo, ou palavra, como o meio pelo qual conduzimos as nossas operações mentais, controlamos o seu curso e as canalizamos em direção à solução do problema que enfrentamos (Vygotsky, 1999, p. 72).

$\mathrm{Na}$ constituição de alguns princípios, salienta-se o conflito entre o conhecimento adquirido em seu cotidiano e o conhecimento científico, que não obstante pareçam antagônicos, não o são; apenas fazem parte de fases de desenvolvimento da criança, desse modo, enquanto criança, ela, de fato, entra em divergência com os conhecimentos cotidianos e os discutidos na escola, no entanto, na proporção que ela se desenvolve, tais oposições deixam de existir, oportunizando um relacionamento mais abrangente, no qual se torna importante a busca pela proximidade entre esses tipos de conhecimento.

\section{Metodologia}

Como vimos o ensino de Física não pode se basear no conteúdo uniforme de transmissão, isto é, uma única passagem do conhecimento através da oralidade sem dispor de instrumentos de ensino, entretanto, deve-se basear em fatos experimentais a partir de procedimentos que levem ao aluno uma melhor compreensão dos conteúdos abordados. 
As aulas foram desenvolvidas nos cursos de Física do $2^{\circ}$ e $3^{\circ}$ ano do ensino médio em uma escola da rede estadual. Durante a aplicação do conteúdo, dividimos a turma em pequenos grupos e os pesquisadores tornaram-se tutores dos alunos em questão, assumindo primeiramente a função mediadora, intervindo quando necessário para esclarecer dúvidas sobre as perguntas como também para corrigir os erros.

As demonstrações experimentais, o uso de instrumentos (data show e materiais experimentais), as justificativas dadas pelos tutores a partir do conhecimento observado dos alunos, os questionamentos propostos, as abstrações da discussão, promoveram situações que estimularam a criatividade dos estudantes, a troca de informações entre eles e a compreensão dos conceitos abordados em sala.

Dessa forma, o conhecimento foi construído a partir das suas percepções cotidianas (que Vygotsky chama de nível de desenvolvimento real) e interação com os novos conceitos (que inicialmente se apresentavam em um nível de desenvolvimento potencial). A partir da mediação entre os tutores e os alunos (atuação na ZDP dos alunos) e entre os próprios alunos (possibilidade de atuação na ZDP uns dos outros), procurou-se facilitar o progresso no aprendizado dos alunos.

Dividimos o conteúdo de Estática dos Fluidos em duas aulas. Tudo isso, para facilitar a abordagem dos temas e acompanhamento da construção dos conhecimentos dos alunos.

\section{Aula 01: Discussão inicial do assunto}

O professor explorou o conhecimento prévio dos alunos sobre conceitos de Massa específica (peso especifico), Densidade (densidade relativa) e Pressão. Desse modo, o assunto foi discutido a fim de propiciar a experiência cultural e real e o contato com o conteúdo ainda desconhecido. Experimentos simples da "flutua ou afunda" ${ }^{5} \mathrm{e}$ aplicações das noções conceituais de pressão foram realizados

\section{Momento 01: Diálogo professor-aluno}

Inicialmente, através de questionamentos e experiências sugeridas pelo professor, os alunos eram convidados a expor as suas compreensões sobre o tema conforme sua visão de mundo (NDR).

\footnotetext{
${ }^{5}$ Para confecção do experimento "flutua ou afunda", é necessário: um recipiente grande cheio de água (bacia ou balde); objetos com diferentes tamanhos e pesos (borracha, lápis, pedaços grandes de isopor etc.). A densidade determina a quantidade de matéria que está presente em uma unidade de volume. Neste caso, quando a densidade for maior o objeto afunda e quando a densidade for menor flutua.
} 


\section{Momento 02: Organização dos conceitos abordados}

Nessa parte, o desenvolvimento do pensamento conceitual foi estimulado na medida em que novos conceitos foram sendo expostos, provavelmente a maioria deles ainda não apropriados pelos alunos (NDP). A demonstração da expressão de diferença de pressão da coluna do líquido propiciou aos discentes a relação de um conceito fundamental: o Teorema de Stevin (Empuxo). A partir disso, foram explanadas algumas consequências deste Teorema (Vasos comunicantes) no dia a dia.

\section{Aula 02: Inclusão do experimento "braço hidráulico"}

Com o uso do experimento do "braço hidráulico"6 e sobre a orientação dos tutores, os alunos foram levados à reflexão, sendo apoiados na construção de novos conhecimentos e habilidades daquilo que eles trazem sobre as relações de força e área, incidindo assim na ZDP dos mesmos.

\section{Momento 01: Diálogo professor-aluno}

Os conhecimentos já desenvolvidos de Empuxo e Peso do corpo ofereceram a construção de novos questionamentos que possibilitaram a troca de informações entre os próprios alunos e também com os tutores, sendo, então, explanado o Princípio de Arquimedes (Peso Aparente e Corpos Flutuantes).

\section{Momento 02: Proposta de atividade.}

Foi proposta aos alunos, uma pesquisa avaliativa sobre as aplicações (tecnológicas, industriais, fabris) e presença das ideias que norteiam os estudos sobre estática dos fluidos. Com isso, observou-se a contextualização do tema e sua importância no meio social dos estudantes e da sociedade, em geral, procurando com isso a construção de sentido pelos mesmos. Dessa forma, podemos perceber que existe uma estreita relação entre aprendizado e desenvolvimento, ou seja, o aprendizado ocorrido em meio à interação social e mediado pela linguagem simbólica permite ao indivíduo o desenvolvimento das suas funções psicológicas. Como diz Vygotsky (1984), a linguagem é constitutiva da cognição humana. 


\section{Resultados e Discussões}

Tendo em vista a complexidade do campo de estudo enfocado, a Física, a abordagem proposta demonstrou possibilitar a análise no que se refere às práticas pedagógicas nas aulas de Física numa escola da rede estadual. As aulas ministradas foram pensadas a partir da perspectiva de Vygotsky sobre aprendizado e desenvolvimento, de forma que ideias inovadoras e criativas sobre o tema em questão, Fluidos, acabaram por provocar um novo interesse dos discentes pelo assunto além de uma construção do conhecimento aparentemente mais contextualizada e, portanto, com mais sentido para os mesmos.

Outro fator importante em destaque foi a apropriação dos alunos dos conhecimentos assimilados na primeira aula, isso por sua vez, teve um aspecto contribuinte, se for levado em consideração que eles puderam estudar os conteúdos para próxima aula, fazendo com que os discentes argumentassem a respeito das possíveis explicações para resposta. Desse modo, utilizamos outras informações que mediaram o aluno a chegar ao pensamento mais cientifico dos assuntos estudados. A participação, em grupo, entre os aprendizes foi bastante significativa em relação a conflitos de entendimento do conteúdo que foram surgindo norteando, assim, um momento propício ao aprendizado.

Baseados nas experiências apresentadas, em suma, podemos afirmar que a oportunidade dada aos alunos de opinarem frente às situações problemas, buscarem soluções, discutir com seus colegas a melhor maneira de esclarecer um fenômeno é um momento de aprendizagem que vai muito além dos conteúdos de Física, mas de cidadania, posicionamento crítico, respeito à opinião distinta dos colegas, por fim, comprometimento com o aprendizado para a vida (Vianna, 2013).

Além disso, a utilização dos materiais apresenta um ganho no ensino de ciências e, no que lhe concerne, está relacionada à estrutura curricular no contexto programático escolar. A proposta de ensino sobre Estática dos fluidos deu prioridade ao uso de experimentos como uma maneira a qual contribuiu para discutir as dúvidas dos alunos, visto que damos importância ao fato de o estudante construir seu conhecimento, levantando hipóteses e testando-as, num contexto de discussão em grupo. Os aprendizes, então, devem ter a possibilidade de construir o seu próprio conhecimento científico, partindo de seus conhecimentos prévios e da realidade em que estão inseridos (Lemos, 2008).

Observamos nas aulas que os alunos apresentaram maior facilidade nos conceitos básicos de Densidade e Pressão, porém apresentaram dificuldades em diferenciar Massa especifica e Densidade. Este obstáculo era por vezes superado a partir da interação entre os alunos no grupo, visto que o ambiente da aula proporcionou aos estudantes condições para, 
voluntariamente, quererem compartilhar o conhecimento adquirido e desenvolvido. Todavia, quando a dificuldade permanecia, abria-se espaço para discussão dos conceitos envolvidos, proporcionando ao aluno o esclarecimento imediato de seus erros qualificando a interação professor-aluno que elaborava a explicação partindo especificamente do erro apresentado.

\section{Conclusão}

Refletir sobre as implicações da teoria sócio-histórico-cultural de Vygotsky ao processo de desenvolvimento do indivíduo em um ambiente de ensino e de aprendizagem nos fez propor o uso de métodos que facilitassem a mediação entre professor e aluno e entre os próprios alunos. Percebemos que o papel do outro, mediado pela linguagem e o uso de experimentos correspondeu às expectativas no que se refere aos resultados que puderam ser observados após a atividade.

Os alunos tiveram uma melhor compreensão sobre a temática abordada, visto que, os tutores, ao levarem em consideração a zona de desenvolvimento proximal de seus alunos, oportunizaram que os mesmos participassem das aulas como agentes participativos e críticos do próprio processo de aprendizagem e de seus colegas. Postura bastante diversa se comparada à passividade com que os alunos são levados a adotar quando diante de atividades de ensino tradicional no qual o professor apenas transmite o conteúdo sem se preocupar com o entendimento construído pelo discente.

\section{Referências}

LEMOS, M.V.; ARAÚJO, R.R.; PEREIRA, A.P.S. Inovando o Ensino de Física através de aulas experimentais, 2008.

MONTEIRO, C.E.; DE CHIARO, S. Fundamentos Psicológicos do Ensino e da Aprendizagem. Recife: Editora Universitária, 2012.

VIANNA, Denise. Temas de física para o ensino médio com enfoque CTS (ciênciatecnologia-sociedade). Enseñanza de las ciencias: revista de investigación y experiencias didácticas, n. Extra, p. 3680-3684, 2013.

VYGOTSKY, L. S. Pensamento e linguagem. 2. Ed. São Paulo: Martins Fontes, 2000.

VYGOTSKY, L. S. Pensamento e linguagem. São Paulo: Martins Fontes, 1999.

VIGOTSKY, L. S. Pensamento e Linguagem. São Paulo: Martins Fontes, 1987.

VYGOTSKY, L. S. A Formação Social da Mente: o desenvolvimento dos processos psicológicos superiores. São Paulo: Martins Fontes Editora, 1984. 